\title{
Resenha
}

\section{O EGO E O DESEJO}

(Do livro: OSHO (2006). Come, Come, Yet Again Come . Cap. 4.

Tradução de Sw. Bodhi Champak. Suiça: Osho International Foundation)

Gislene Farias de Oliveira (1)

Este texto discorre sobre as dúvidas de uma jovem, que certa vez perguntou ao mestre Osho, se ele saberia explicar o que ela realmente queria? Ao que o mestre de pronto respondeu: “...ninguém sabe exatamente o que quer, porque ninguém está consciente nem mesmo de quem se é. A questão do querer é secundária, a questão básica é: quem é você? A partir disso, as coisas poderão ser resolvidas - quais são seus desejos, suas vontades, suas ambições?".

E continuou. "Se você é um ego, então naturalmente você quer dinheiro, poder, prestígio, quer lutar com outras pessoas, você será competitivo - ambição significa competição. Você estará continuamente pisando na garganta dos outros e eles estarão continuamente pisando na sua. Então a vida se torna aquilo que Charles Darwin disse: a sobrevivência dos mais aptos".

$\mathrm{Na}$ verdade o uso que ele faz da expressão "os mais aptos" não é correto. $\mathrm{Na}$ verdade, o que ele chama de mais apto, é o mais esperto, o mais animalesco, o mais inflexível, o mais estúpido, o mais feio. Charles Darwin não diria que Buda é o mais apto, ou Jesus, ou Sócrates. Essas pessoas seriam mortas facilmente e aqueles que os tivessem matado iriam sobreviver. Jesus não conseguiria sobreviver. Certamente, de acordo com Darwin, Jesus não é a pessoa mais apta. Poncios Pilatos é muito mais apto, estaria no caminho certo. Sócrates não era o mais apto, mas as pessoas que o envenenaram, que o condenaram à morte, eram. $\mathrm{O}$ uso que ele faz da expressão ‘o mais apto’ é muito infeliz, segundo Osho.

Osho acreditava que se você está vivendo no ego, então a sua vida será uma luta; ela será violenta e agressiva. Você criará miséria para os outros e para si mesmo, porque a vida de conflito não consegue ser nada além disso. Explica que dessa forma, tudo depende de você, de quem você é. Se você está no ego, ainda pensando em si em termos de ego, então você terá uma certa qualidade fétida. Mas, se você chegou a compreender que você não é um ego, então 
a sua vida terá um perfume especial. Se você não conhece a si mesmo, você está vivendo na inconsciência, e uma vida de inconsciência só pode ser uma vida de equívocos.

Ele quer dizer que, a pessoa pode ouvir qualquer mestre que queira eleger, mas sempre interpretará de acordo com a sua própria inconsciência. Muitas vezes de forma distorcida.

Segundo Osho, o cristianismo seria uma má interpretação de Jesus, assim como o budismo uma má interpretação de Buda. Todas essas religiões são interpretações errôneas, distorções, porque as pessoas que seguem Jesus ou Buda, são pessoas comuns sem consciência. O que elas fazem é preservar os escritos e matar o espírito.

Ele conta uma história para explicar sua idéia:

"Um filósofo estava caminhando ao redor de um parque e notou um homem sentado em posição de lótus, com os olhos abertos olhando para o chão. O filósofo viu que o homem estava totalmente absorvido em seu olhar fixo ao chão. Depois de observá-lo por um longo tempo, o filósofo não mais resistiu e foi até o estranho camarada perguntando, 'O que você está procurando? O que está fazendo?".

Então o homem respondeu sem deslocar o seu olhar fixo, "Eu estou seguindo a tradição Zen de sentar silenciosamente, nada fazer e então a primavera vem e a grama cresce por si mesma. Eu estou observando a grama crescer, mas ela ainda não cresceu coisa alguma”.

E ele explica: não é preciso observar a grama crescer - mas isso é o que sempre acontece. Jesus diz uma coisa e as pessoas escutam, mas elas escutam apenas as palavras e dão àquelas palavras os seus próprios significados.

Osho dá outro exemplo metafórico: "Uma mãe levou seu filhinho ao psiquiatra e por mais de três horas ela lhe contou toda a história de seu filho. O psiquiatra estava ficando cansado, mas a mulher estava tão absorvida na sua fala que nem mesmo the deu oportunidade de impedi-la. Uma frase seguia a outra sem qualquer intervalo. Finalmente o psiquiatra teve que dizer: Por favor, pare agora! Deixe-me perguntar algo ao seu filho!. E ele perguntou ao filho: Sua mãe está reclamando que você não ouve o que ela lhe diz. Você tem alguma dificuldade de audição?. O filho disse: Não. Eu não tenho dificuldade de audição os meus ouvidos estão perfeitamente bem - mas no que se refere a escutar, você pode julgar por si mesmo".

Ele explica que ouvir é algo sensorial, mas escutar é algo mais profundo, psicológico. Você pode ouvir toda sorte de coisas e escutar apenas o que sua cognição permitir. 
Ele continua a explicação à jovem, mostrando que o que a pessoa quer, é uma questão de ponto de vista, de referencial. Por exemplo: Se você estiver identificado com o corpo, então o seu querer será diferente; então comida e sexo serão suas únicas vontades, seus únicos desejos. Esses são dois desejos animais. Mas se você estiver identificado com a mente, os seus desejos serão diferentes: música, dança, poesia, e depois existem mil coisas.

Osho explica que o corpo é muito limitado; ele tem uma polaridade simples: comida e sexo. Ele se move como um pêndulo entre esses dois, comida e sexo, como se nada mais existisse para ele. Mas se você está identificado com a mente, então ela tem muitas dimensões. Você pode estar interessado em filosofia, em ciência, em religião - você pode estar interessado em muitas coisas que consegue imaginar.

Se você estiver identificado com o coração, então os seus desejos serão de uma natureza ainda mais elevada, mais do que a mente. Você se tornará mais estético, mais sensitivo, mais alerta, mais amoroso.

Segundo o mestre Osho, A mente é agressiva, o coração é receptivo. A mente é masculina, o coração é feminino. A mente é lógica, o coração é amor.

Assim, depende da pessoa e de onde ela está se referenciando: no corpo, na mente ou no coração. Esses são os três mais importantes locais nos quais a pessoa pode funcionar. Mas também existiria um quarto local em cada um de nós; no oriente ele é chamado de turya. Turya simplesmente significa o quarto, o transcendental. Se uma pessoa se torna consciente de sua transcendentalidade, então todos os desejos desaparecem. Então a pessoa apenas é, sem qualquer desejo, sem nada para ser pedido, nada para ser atendido. Não existe futuro ou passado. Então a pessoa vive neste momento completamente satisfeita, realizada. Em Turya, o seu lótus de mil-pétalas desabrocha e a pessoa se torna divina.

Quando a pergunta é: 'O que eu quero?' Isso simplesmente mostra que esta pessoa nem mesmo sabe onde está, a que referencial está ligada. Terá que investigar dentro de si mesmo - e isso não é muito difícil.

Quando a comida e o sexo toma a maior parte de você, então eli é onde você está identificado; se é algo que diz respeito ao pensar, então é a mente; se diz respeito a sentimentos, então é o coração. E, naturalmente, esta pessoa não entrou em Turya, senão a pergunta nunca teria surgido.

Assim, a recomendação do Mestre Osho é que, ao invés de perguntar a alguém, onde se está? , pergunte a si mesmo. Investigue. Somente então as coisas podem ficar claras - e isso não é difícil. E continua, “...é sempre bom perguntar algo que seja relevante para você ao 
invés de perguntar algo que não lhe diz respeito. As pessoas me perguntam se Deus existe ou não, e elas nem mesmo sabem se elas existem ou não".

O que ele sugere é que simplesmente olhemos para dentro de nós, para que possamos observar onde exatamente está o nosso problema?.

Primeiro você tem que ver a sua situação, onde você está; somente então você poderá dizer o que você quer.

Investigue, olhe para o lugar exato onde você está. Segundo o autor, todo desejo é completo desperdício, todo querer é errado. Mas se a pessoa está identificada com o corpo, torna-se impossível alguém responder, porque isso estará muito longe do seu alcance. Se a pessoa está identificada com o corpo, deverá mudar um pouco para desejos mais elevados, os desejos da mente, e depois um pouco mais alto, para os desejos do coração, e depois finalmente ao estado sem desejo.

Osho acredita que desejo algum jamais será satisfeito e que esta é a diferença entre a abordagem científica e a abordagem religiosa. A ciência tenta satisfazer os nossos desejos e, naturalmente, a ciência tem sido bem sucedida ao fazer muitas coisas, mas o homem permanece na mesma miséria. A religião tenta acordá-lo para a grande compreensão para que o homem possa ver que todos os desejos intrinsecamente não conseguem ser satisfeitos.

Segundo ele, é preciso ir além de todos os desejos e somente assim haverá contentamento. Contentamento não é o fim de um desejo, contentamento não é a satisfação do desejo; porque o desejo não pode ser satisfeito. Com o tempo, quando a pessoa chegar à satisfação do seu desejo, irá descobrir que mil e um outros desejos surgiram. Cada desejo se ramifica em muitos desejos novos. E isso acontecerá repetidas vezes e toda a sua vida será desperdiçada.

Aqueles que sabem, aqueles que vêem - os budas, os despertos - todos concordam em um ponto. Isso não é uma coisa filosófica, é factual, de fato no mundo mais interior: o contentamento acontece quando todos os desejos tiverem sido abandonados. É com a ausência de desejos que o contentamento surge dentro das pessoas. Na verdade, a própria falta de desejos é contentamento, é preenchimento, é gozo, é florescimento.

Para o autor, o nirvana tem dois significados, mas esses dois significados são como dois lados de uma mesma moeda. Um significado é a cessação do ego e o outro significado é a cessação de todos os desejos. Isso acontece simultaneamente. O ego e os desejos estão intrinsecamente juntos, eles estão inseparavelmente juntos. No momento em que o ego morre, os desejos desaparecem, ou vice-versa: no momento em que os desejos 
são transcendidos, o ego é transcendido. E ser sem desejos, ser sem ego, é conhecer a felicidade suprema, é conhecer o êxtase eterno.

Dessa forma, ele acredita que somos a busca pelo êxtase eterno, a qual começa mas nunca termina.

(1) Gislene Farias de Oliveira é Psicóloga, Doutora em Psicologia Social e Professora da Universidade Federal do Ceará e da Universidade Regional do Cariri.

E-mail: gislenefo@hotmail.com. 